\title{
Peningkatan Kapasitas Petani Melalui Pelatihan Pembuatan Pupuk Organik Bokashi di Daerah Perbatasan Darat Kalimantan Barat
}

\author{
Arief Sirajuddin ${ }^{1}$, Kartika Ekasari $^{2}$, Racmat $^{3}$, Aminuddin Saade $^{4}$ \\ 1,2,3,4Politeknik Pembangunan Pertanian Gowa
}

\begin{abstract}
This activity was motivated by the fact that the people in Mentibar Village, Paloh Sub-district of Sambas Regency are farmers who had only relied on their farming activities using of inorganic fertilizer especially Urea fertilizer from Malaysia, which the price is not cheap and sometimes the unavailable. The farmers in Mentibar village are new to Bokashi organic fertilizer, which its main ingredients are widely available in the village such as livestock, fine bran, straw, etc. In this study, we conducted training and counselling to improve farmers' knowledge and skills in making organic fertilizer. Bokashi as an alternative fertilizer can be used by farmers in their rice cultivation and at the same time to less reliant to inorganic fertilizer. The purpose of this Community Service activities are: First, to increase the knowledge and skills of farmers in making Bokashi organic fertilizer. Second, to provide an understanding that relying on inorganic fertilizer can damage the soil and produce pollution. Third, farmers will be able to utilize the materials around them to be used as Bokashi fertilizers such as livestock, bran, husks and rice straw.
\end{abstract}

Keywords: empowerment, farmers, organic fertilizer, bokashi, land border area of West Kalimantan

\section{PENDAHULUAN}

\section{A. Latar Belakang}

Ketahanan pangan merupkan bagian sangat penting dari ketahanan nasional. Dalam hal ini ha katas pangan seharusnya mendapat perhatian yang sama besar dengan usaha menegakkan pilar-pilar hak asazi manusia lain, untuk mewujudkan kondisi ketahanan pangan nasioanal yang mantab, subsistem ketahan pangan (ketersediaan, distribusi dan konsumsi) dalam sistem ketahanan pangan diharapkan dapat berfungsi sebagai sinergis, melalui kerjasama antar komponen-komponen yang digerakkan oleh pemerintah dan masyarakat.

Untuk mencapai tujuan tersebut diperlukan adanya dukungan kebijakan strategis dan pengaturan teknis agar seluruh sumberdaya, baik sumberdaya manusia maupun sumberdaya alam berfungsi secara harmonis dan optimal. Padi, jagung dan Kedelai serta komoditas strategis pertanian lainnya antara lain aneka cabai, bawang merah, tebu dan sapi potong yang merupakan 7 (tujuh) komoditas hasil pertanian strategis yang seringkali menjadi isu nasional. Kementerian pertanian pada tahun 2016 mentargetkan peningkatan produksi padi minimal 76,2 juta ton GKP, Jagung 21,173 juta ton, kedelai 1,82 juta ton, aneka cabai 1,1 juta ton, bawang merah 1,173 juta ton, tebu 3,2 juta ton dan daging sapi 0,552 juta ton. Untuk mencapai semua target diatas maka diperlukan input sarana produksi yang cukup berupa pupuk, bibit, alat dan mesin pertanian selain itu diperlukan juga sarana produksi alternative seperti pupuk organic, ZPT, pestidisa, herbisida dan sarana produksi lainnya, selain itu diperlukan penyebaran informasi teknologi yang sifatnya mendukung dari beberapa target diatas seperti penyuluhan dan pelatihan-pelatihan bagi petani dan pelaku utama lainnya sangat diperlukan.

Dalam implementasi pencapaian target peningkatan produksi komoditas tersebut disadari adanya beberapa keterbatasan sebagai faktor pembatas, antara lain adalah petani dan penyuluh pertanian, dimana jumlah penyuluh pertanian pada dasawarsa terakhir ini mengalami penurunan yang nyata karena pensiun, alih fungsi ke non penyuluh pertanian dan rendahnya rekruitmen penyuluh. Mengingat kondisi tersebut, maka diperlukan upaya strategis, antara lain penyapan tenaga 
energik dan mandiri yang dapat membantu kinerja penyuluh dan pendampingan kepada petani. Upaya tersebut didukung dengan implementasi secara nyata dilapangan dengan memberikan perhatian yang serius dari semua pihak, termasuk perguruan tinggi sebagai komunitas masyarakat akademis, dalam hal ini adalah civitas akademika yang terdiri atas dosen dan mahasiswa.

Keterlibatan civitas akademik dalam hal ini dosen dan mahasiswa dilaksanakan dalam bentuk kegiatan Pengabdian Kepada Masyarakat (PKM) dan Praktek Kerja Lapangan (PKL) II, yang merupakan salah satu Tridarma Perguruan Tinggi dan salah satu kurikulum pembelajaran bagi mahasiswa tingkat III di Politeknik Pembangunan Pertanian Gowa.

Desa Mentibar, Kecamatan Paloh yang merupakan salah satu kecamatan di kabupaten Sambas Propinsi Kalimantan Barat merupakan salah satu wilayah yang menjadi target pencapaian swasembada pangan, tepatnya di kawasan perbatasan darat Indonesia dan Malaysia.

Kegiatan Pengabdian Kepada Masyarakat di Daerah Perbatasan Darat ini diharapkan dapat meningkatkan produksi pertanian dan keterampilan petani yang berimplikasi pada meningkatnya pertumbuhan ekonomi masyarakat diwilayah ini utamanya pada bidang pertanian. Selain itu melalui kegiatan PKM dan PKL II diharapkan dapat memotivasi petani dan pemuda tani untuk lebih mencintai dunia pertanian, sehingga secara tidak langsung terjadi peningkatan sumberdaya manusia didaerah perbatasan. Kegiatan PKM yang utamanya adalah penyebaran informasi terkait dengan penggunaan dan pembuatan pupuk Bokashi Jerarami padi.

Pemupukan dengan bahan organik sangat mendukung upaya melestarikan produktivitas lahan dan menjaga ketersediaan bahan organik dalam tanah. Pupuk organik adalah pupuk yang berasal dari bahan organik dari tumbuhan dan hewan. Manfaat pupuk organik antara lain dapat mengurangi penggunaan pupuk anorganik, memperbaiki struktur tanah serta mengefektifkan serapan unsur hara. Pupuk bokashi merupakan salah satu jenis pupuk organik yang dapat digunakan. Pupuk bokashi adalah suatu kata dalam bahasa Jepang yang berarti bahan organik yang telah difermentasikan. Bokashi dibuat dengan memfermentasikan bahan organik dengan Effective Microorganisme (EM) yang merupakan kultur campuran dari berbagai mikroorganisme yang menguntungkan bagi pertumbuhan tanaman yang terdiri dari bakteri asam laktat, bakteri fotosintetik Actinomycetes, ragi dan jamur. Fungsi dari pupuk bokashi itu sendiri adalah untuk meningkatkan keragaman mikroba dalam tanah dan meningkatkan ketersediaan unsur hara bagi tanaman.

\section{B. Tujuan dan Manfaat}

1. Meningkatkan koordinasi dan keterpaduan pelaksanaan tercapainya swasembada pangan.

2. Mempercepat penerapan teknologi PTT/spesifik lokasi oleh petani sehingga dapat meningkatkan pengetahuan dan keterampilan dalam mengelola usaha taninya.

3. Menambah pengetahuan dan keterampilan petani dalam hal membuat pupuk organik Bokashi.

4. Meningkatkan sumberdaya manusia pertanian di wilayah perbatasan.

\section{METODE PELAKSANAAN}

\section{A. Tempat dan Waktu}

Pengabdian kepada masyarakat di Desa Mentibr, Kecamatan Paloh, Kabupaten Sambas dilaksanakan pada tanggal 7 sampai 8 April 2018. Para peserta berasal dari para petani padi, sayuran, dan peternak sapi . Jumlah petani yang hadir 24 orang. Tempat pertemuan di rumah Ketua Kelompok dari pagi (jam 8.00 wib) sampai dengan sore (jam 16.00 wib). Bahan-bahan yang dibutuhkan dalam pertemuan dengan para petani berupa LCD, folder/leafled buku teknologi tepat guna berjudul: Pupuk Bokasi. Buku ini dihibahkan untuk pemerintahan desa Mentibar agar dapat digunakan untuk kepentingan para petani di Mentibar.

\section{B. Metode Pelaksanaan}

Dalam proses penyuluhan/penyampain informasi maka metode yang digunakan adalah ceramah dan diskusi serta demonstrasi cara, metode ini 
sangat efektif karena petani bisa langsung mempraktekkan dan langsung bertanya jika ada hal yang tidak dimengerti.

\section{HASIL DAN PEMBAHASAN}

Pertemuan antara pengabdi (dosen 3 orang) dengan para petani di Desa Mentibar Kecamatan Paloh, Kabupaten Sambas, Propinsi Kalimantan Barat berjalan sangat baik. Ketika kami, pengabdi tiba di kantor Kepala Desa Mentibar kami disambut oleh Kepala desa, Sekretaris desa, perangkat desa yang lain, dan para petani. Para petani yang hadir berasal dari petani dari desa Mentibar dengan pekerjaan sebagai petani. Kami pertama kali dikenalkan oleh Kepala Desa Mentibar kepada para petani termasuk perangkat desa. Mulai dari mengenalkan nama masingmasing pengabdi, maksud dan tujuan, dan kegiatan yang dilakukan selama berada di Desa Mentibar. Kemudian kami mendengarkan juga perkenalan para perangkat desa yang hadir. Selanjutnya dikenalkan juga pekerjaan dan asal para petani yang berada di desa.

Pembukaan pertemuan antara pengabdi dan para petani di desa dilakukan oleh Kepala Desa Mentibar. Selanjutnya pemaparan cara pembuatan dan pemanfaatan pupuk Bokasi untuk meningkatkan produksi pertanian dibawakan oleh pengabdi secara bergantian selama 60 menit dan dilanjutkan dengan diskusi dan Tanya-jawab antara pengabdi dan para petani. Pertemuan ini sangat lancar dengan adanya interaksi yang baik antara pengabdi dan para petani. Banyak sekali pertanyaan yang dilontarkan oleh para petani kepada pengabdi. Pengabdi berusaha menjawab pertanyaan dengan sebaik-baiknya. Ada sekitar 10-15 pertanyaan yang dilontarkan oleh para petani dan dijawab oleh pengabdi dengan baik. Akhir pertemuan dan
Tanya-jawab dilakukan foto bersama-sama dan pemberian folder/leafled yang telah dibuat oleh tim pengabdi.

\section{KESIMPULAN}

Dalam laporan ini kami dapat menarik beberapa kesimpulan yaitu:

a. Perlu kiranya kegiatan seperti ini dilestarikan untuk memberikan ilmu dan pengetahuan,serta teknologi yang sederhana dan tepat sasaran kepada para petani sehingga dapat diharapkan adanya perubahan sikap dan perilaku para petani dari bertani sekedarnya kepada para petani yang gigih, kerja keras, inovatif, dan mau kerja sama antar kelompok tani.

b. Politeknik Pembangunan Pertanian Gowa melalui Unit Penelitian dan Pengabdian Kepada Masyarakat (UPPM) dapat menjalankan fungsi Tridharma Perguruan dengan sebaik-baiknya sebagai koordinator pengabdian kepada masyarakat melalui penerapan ilmu dan teknologi pertanian yang dihasilkan melalui penelitian di Perguruan Tinggi.

c. Pemerintah utamanya Dinas Pertanian Kabupaten Paloh dan Balai Penyuluhan Pertanian Kabupaten Paloh diharapkan agar dapat memfasilitasi kebutuhan sarana prasarana petani sehingga petani dapat berusaha tani dengan baik dan diharapkan kepada aparat pemerintah terkait agar dapat meningkatkan proses difusi teknologi pertanian.

d. Ke depan dapat direncanakan kerjasama antara Politeknik Pembangunan Pertanian Gowa dengan pemerintah desa Mentibar dalam program Pangan-Pertanian menuju petani yang andal dan cerdas. 